\title{
AKTIVITAS PEMASARAN PRODUK TABUNGAN PADA PT. BPR RANGKIANG DENAI PAYAKUMBUH BARAT
}

\author{
Muhamad Rahman, Ratna Widayati \\ Akademi Keuangan dan Perbankan Padang \\ ratnawidayati@akbpstie.ac.id
}

\begin{abstract}
This study aims to determine how the savings product marketing activities undertaken by PT. BPR Rangkiang Denai, and the development of savings products at PT. BPR Rangkiang Denai. This research method is based on primary and secondary data. while the data collection techniques by observation, interviews, and based on the literature. So we can conclude marketing efforts conducted BPR Rangkiang Denai to increase the number of customers, by way of the marketing mix: Product, Price, Promotion, Place, People, Processes, Services and development of savings products at PT. RB Rangkiang Denai experienced a significant decline, it is because in contemporary times, $R B$ is less interested in the community because in the era of globalization people prefer banks that provide services in payment traffic, such as remittances, and ATM facilities to facilitate the transaction.
\end{abstract}

Keywords: savings product marketing activities

\section{LATAR BELAKANG}

Dalam melakukan kegiatan perekonomian diperlukan dana yang besar, sehingga pemerintah mampu menciptakan langkah-langkah baru di bidang perekonomian dengan tujuan dapat mencapai sasaran pembangunan dan pertumbuhan ekonomi. Pemerintah juga harus mampu menciptakan kebijakankebijakan agar bank dapat dimanfaatkan oleh pelaku ekonomi.

Menurut Pasal 1 Undang-undang Nomor 10 tahun 1998 tentang perbankan, Bank adalah badan usaha yang menghimpun dana masyarakat dalam bentuk simpanan dan menyalurkannya pada masyarakat dalam bentuk kredit atau bentuk-bentuk lainnya dalam rangka meningkatkan taraf hidup rakyat banyak.

Menurut Pasal 5 (ayat 1) UU No. 7 tahun 1992, terdapat dua bentuk bank berdasarkan jenisnya, yaitu Bank Umum dan Bank Perkreditan Rakyat. Bank umum adalah Bank yang melakukan kegiatan usahanya seacara konversional atau berdasarkan prinsip syariah yang dalam kegiatannya memberikan jasa lalulintas pembayaran. Sebagaimana halnya fungsi dan tugas perbankan di Indonesia. Bank Umum juga merupakan agent of development yang bertujuan meningkatkan pemerataan, pertumbuhan ekonomi dan stabilitas nasional kearah peningkatan kesejahteraan rakyat banyak.

Sedangkan Bank Perkreditan Rakyat adalah Bank yang melaksanakan kegiatan usahanya secara konvensional atau berdasarkan prinsip syariah yang 
dalam kegiatannya tidak memberikan jasa dalam lalulintas pembayaran. Bank Perkreditan Rakyat mempunyai kegiatan usaha yang lebih terbatas dibandingkan dengan Bank Umum. Bank Perkreditan Rakyat hanya menerima simpanan dalam bentuk deposito berjangka, Tabungan, dan bentuk lain yang dipersamakan dengan itu dan tidak menerima penghimpunan dana dalam bentuk giro. Bank Perkreditan Rakyat juga tidak diperbolehkan melakukan pernyertaan modal, kegiatan usaha dalam modal asing serta kegiatan perasuransian.

Bank Perkreditan Rakyat pada mulanya diarahkan untuk mendorong pertumbuhan dan modernisasi ekonomi di daerah pedesaan. Dengan semakin berkembangnya kebutuhan masyarakat, Bank Perkreditan Rakyat tidak hanya ditujukan untuk masyarakat golongan ekonomi menengah kebawah di daerah pedesaan namun juga ditunjukkan didaerah perkotaan.

Pemasaran merupakan salah satu aspek yang sangat penting dalam keberhasilan suatu perusahaan perbankan. Selain itu kebijaksanaan pemasaran diperlukan karena terjadinya liberalisasi di bidang perbankan yang telah mendorong munculnya bank-bank baru dan cabang-cabang bank asing di Indonesia, sehingga persaingan antar bank dalam memperebutkan pasar perbankan semakin ketat.

Pada umumnya tujuan dari kegiatan pemasaran adalah mempengaruhi konsumen agar bersedia membeli produk pada saat mereka membutuhkanya. Oleh karena itu, setiap perusahaan harus berusaha meningkatkan pelayanan sebagai prasarana dan barang sebagai penyangga dalam menarik hati atau minat nasabah.

Pemasaran bank merupakan pemikiran yang berorietasi kepada nasabah, sehingga, kebutuhan dan keinginan nasabah dapat dipenuhi. Dengan kata lain, yang menjadikan sasaran pemasaran adalah nasabah. Penyediaan keinginanan dan kebutuhan terhadap produk bank ini harus dilakakukan melalui perencanaan jangka panjang maupun jangka pendek sehingga memudahkan terjadinya kegiatan pemasaran.

\section{Pengertian Pemasaran}

Pengertian pemasaran menurut WY. Stanton, pemasaran adalah sesuatu yang meliputi seluruh sistem yang berhubungan dengan tujuan untuk merencanakan dan menentukan harga sampai dengan mempromosikan dan mendistribusikan barang dan jasa yang bisa memuaskan kebutuhan pembeli aktual maupun potensial. Sedangkan menurut H. Nistrom, Pemasran adalah suatu kegiatan penyaluran barang dan jasa dari tangan produsen ke tangan konsumen.

Menurut Philip dan Duncan pemasaran yaitu sesuatu yang meliputi semua langkah yang dipakai atau dibutuhkan untuk menempatkan barang yang bersifat tangible ke tangan konsumen. Asosiasi Pemasaran Amerika Serikat / American Merketing Association mengartikan pemasaran sebagai pelaksanaan kegiatan usaha perdagangan yang diarahkan pada aliran barang dan jasa dari produsen ke konsumen (organisasi.org).

Pemasaran adalah system keseluruhan kegiatan usaha yang ditujukan untuk merencanakan, menentukan harga, mempromosikan dan mendistribusikan barang dan jasa yang dapat memuaskan kebutuhan pembeli yang ada maupun pembeli potensial (Dharmmesta,1996). 


\section{Rumusan Masalah}

Berdasarkan latar belakang yang telah diuraikan di atas, maka rumusan masalah dalam penelitian ini adalah " bagaimana aktivitas pemasaran produk tabungan PT. Bank Perkreditan Rakyat Rangkiang Denai Payakumbuh Barat"

\section{TINJAUAN PENELITIAN \\ Pengertian Bank}

Menurut Undang- Undang No.10 Tahun 1998 tentang perubahan Undangundang No.7 Tahun 1992 tentang perbankan, bank adalah badan usaha yang menghimpun dana dari masyarakat dalam bentuk simpanan dan menyalurkan pada masyarakat dalam bentuk kredit dan atau dalam bentuk-bentuk lain dala rangka meningkatkan taraf hidup rakyat banyak.

\section{Strategi Pemasaran}

Istilah strategi pemasaran banyak digunakan orang terutama dalam bidang bisnis, yaitu dalam hal membicarakan prosedur dan strategi. Istilah strategi sebenarnya berasal dari bahasa yunani yang artinya kepemimpinan. "strategi pemasaran adalah keseluruhan tindakan-tindakan yang disiapkan oleh sebuah organisasi untuk mencapai sasaran-sasarannya." (Philip kotler, 1992)

Strategi pemasaran berkaitan dengan masalah bagaimana menetapkan bentuk penawaran pada segment pasar tertentu. Hal ini dapat dipenuhi dengan penyediaan suatau sarana yang disebut bauran pemasaran yang merupakan inti dari sistem pemasaran bank.

Untuk dapat menunjang peneningkatan jumlah nasabah atau konsumen maka diperlukan suatu strategi pemasaran yang tepat dan terarah sebagai berikut :

1. Strategi Berdasarkan Segmentasi Pasar

Yaitu dengan membagi pasar kedalam kelompok-kelompok sejenis dan memilih yang paling sesuai bagi bank dalam upayanya memberikan pelayanan yang terbaik dan menarik bagi nasabah. Misalnya, untuk kelompok pengusaha diperkenalkan giro dan untuk pelajar diperkenalkan produk tabungan.

2. Strategi Pemasaran Berdasarkan Market positioning

Yaitu dengan menambah ciri-ciri tertentu bagi produk-produk antara lain memudahkan persyaratan menabung dan penarikan tabungan serta memberikan tingkat bunga yang tetap bersaing dengan tingkat bunga pasar.

3. Strategi Berdasarkan Struktur Pasar

Bagi suatu perusahaan sebelum menawarkan dan memasarkan, biasanya terlebih dahulu harus mengetahui peluang dan potensi pasar tersebut, maka perusahaan akan dapat memperkirakan tingkat penjualan yang akan di capai. Salah satu cara untuk melihat peluang dan potensi tersebut yaitu dengan mempelajari struktur pasar, sebab struktur pasar ini merupakan pedoman dalam menyusun strategi dalam menghadapi persaingan.

Strategi untuk menetapkan keputusan yang berhubungan dengan pemasaran adalah strategi produk. Strategi produk dipakai oleh perusahaan untuk mengubah atau menyempurnakan produk yang ada sekarang menjadi bentuk yang lebih baik. Sehingga produk perusahaan tidak kalah dengan produk milik pesaing dan sesuai dengan produk kebutuhan dan selera konsumen. 
Strategi promosi juga merupakan suatu bagian yang sangat penting. Promosi adalah suatu cara langsung untuk mempengaruhi konsumen agar lebih suka membeli merk barang tertentu. Untuk strategi harga pada umumnya bank menetapkan harga atau bunga dengan berbagai tujuan :

1. Memperoleh laba maksimal, bank menentukan harga sendiri dengan tujuan memperoleh laba secara maksimal.

2. Bank menetapkan suatu kebijakan harga yaitu menetapkan harga yang sama kepada semua konsumen dan jumlah yang sama.

Menurut kasmir (2000) sarana bank dalam mempromosikan produknya ada empat cara yaitu :

1. Periklanan (advertising)

Iklan adalah sarana promosi yang digunakan oleh bank guna menginformasikan, menarik, dan mempengaruhi calon nasabahnya. Penggunaan promosi dengan iklan dapat dilakukan dengan berbagai media seperti melalui :

a. Pemasangan billboard di jalan-jalan strategis.

b. Pencetakan brosur disebarkan setiap cabang maupun di pusat-pusat perbelanjaan.

c. Pemasangan spanduk dilokasi tertentu yang strategis.

d. Pemasangan melalui Koran, televisi, radio, dll.

2. Promosi Penjualan (Sales Promotion)

Tujuan promosi penjualan adalah untuk meningkatkan penjualan atau untuk meningkatkan jumlah nasabah. Bagi bank promosi penjualan dapat dilakukan melalui :

a. Pemberian bunga khusus (special rate) untuk jumlah dana yang relative besar.

b. Pemberian insentif untuk setiap nasabah yang memiliki saldo dengan jumlah tertentu.

c. Pemberian cinderamata.

3. Publisitas (publicity)

Publisitas adalah kegiatan promosi untuk memancing nasabah melalui kegiatan seperti pameran, bakti sosial serta kegiatan lainya yang melalui berbagai media.

4. Penjualan pribadi (personal selling)

Kegiatan personal selling dilakukan oleh semua pegawai bank, secara khusus personal selling dilakukan oleh customer service.

\section{METODE PENELITIAN}

Dalam pengumpulan data dan bahan untuk melakukan penelitian ini, digunakan metode-metode pengumpulan data sebagai berikut :

1. Studi Kepustakaan

Penelitian ini dilakukan dengan mengumpulkan data dan menggunakan teori-teori yang berkaitan dengan masalah-masalah yang akan di bahas, yang di peroleh dari literature yang ada berupa buku-buku yang berkaitan dengan masalah.

2. Studi lapangan

Pada penelitian ini dilakukan dengan cara melakukan pengamatan langsung dan melakukan wawancara dengan pihak-pihak yang terkait. 


\section{HASIL DAN PEMBAHASAN}

\section{Bauran Pemasaran Produk Tabungan Pada PT. BPR Rangkiang Denai}

Pemasaran sudah merupakan kebutuhan utama dan suatu keharusan bagi dunia perbankan dalam mempertahankan kelangsungan hidupnya, sehingga berkembang dan mendapatkan laba. Pentingnya pemasaran dilakukan dalam rangka memenuhi kebutuhan dan keinginan masyarakat akan suatu produk atau jasa. Pemasaran menjadi semakin penting dilakukan dalam rangka menghadapi pesaing yang diberi waktu kewaktu semakin meningkat. Berhasil tidaknya dalam pencapaian tujuan perusahaan tergantung pada pengelolaan yang harus dilakukan secara profesional sehingga kebutuhan dan keinginan pelanggan akan segera terpenuhi dan terpuaskan.

Bauran pemasaran yang dilakukan untuk meningkatkan jumlah nasabah sebagai berikut :

\section{A. Produk}

Produk yang diinginkan nasabah adalah produk yang berkualitas tinggi, sehingga bank dituntut agar memodifikasi produk yang sudah ada menjadi lebih menarik. Pada PT. BPR Rangkiang Denai, Produk tabungannya adalah TAMADES Produk ini cukup populer pada bank tersebut.

PT. BPR Rangkiang Denai memasarkan TAMADES (Tabungan Masyarakat Desa) ini pada masyarakat Payakumbuah Barat, TAMADES ini dibuat agar masyarakat Payakumbuh Barat mau menabung karena keunggulan yang dimiliki, BPR Rangkiang Denai memberikan bonus berupa alat-alat elektronik seperti Kulkas, Mesin cuci, TV dll bagi nasabah yang memiliki saldo tabungan tertinggi, Ini diundi setiap satu kali dalam sebulan. BPR Rangkiang Denai juga melakukan undian satu kali dalam setahun dengan hadiah satu unit Sepeda Motor bagi saldo tabungan tertinggi. Ini bertujuan agar calon nasabah baru tertarik untuk membuka tabungan TAMADES, dan pemilik tabungan TAMADES merasa termotivasi untuk selalu meningkatkan saldo tabungannya.

B. Harga (price)

BPR Rangkiang Denai menetapkan harga berdasarkan nasabah utama (primer) atau nasabah biasa (sekunder), nasabah primer adalah nasabah yang loyal dan memiliki saldo diatas Rp. 50.000 .000 dan sesuai kriteria yang ditetapkan oleh bank. Sedangkan nasabah sekunder adalah nasabah umum yang memiliki saldo tabungan di bawar Rp. 50.000.000. Bagi nasabah primer Pada BPR Rangkiang Denai tidak dikenakan biaya administrasi untuk bank.

C. Promosi (promotion)

Kegiatan promosi yang dilakukan oleh PT. BPR Rangkiang Denai untuk memasarkan produknya pada seluruh lapisan masyarakat adalah sebagai berikut :

1. Periklanan

Media iklan yang dipakai PT. BPR Rangkiang Denai melalui media elektronik, yaitu melalui radio. Dengan tujuan untuk mempertahankan nasabah yang ada dan untuk menjaring nasabah baru.

2. Mengeluarkan brosur-brosur tentang keunggulan dari suatu produk yang ditawarkan oleh PT. BPR Rangkiang Denai dan juga memperlihatkan tingkat bunga dari masing-masing produk tersebut.

3. Melakukan informasi dari mulut ke mulut 
4. Memberikan hadiah kepada nasabah melalui undian-undian yang dilakukan satu kali dalam satu tahun.

D. Lokasi (distribution)

Dalam pendistribusian produk atau jasa-jasa bank, perlu adanya lokasi kantor yang tepat yang didukung oleh pemasaran yang terpadu. PT. BPR Rangkiang Denai, berpusat di Jln. Soekarno-Hatta No 01 Kel. Daya Bangun , Kota Payakumbuh, Sumatra Barat.Telp (0752)-90385 Fax. (0752) 95636.

Lokasi kantor PT. BPR Rangkiang Denai sangat strategis karena berpusat di jantuang Kota Payakumbuh. Penempatan dan pendistribusian yang digunakan oleh PT. BPR Rangkiang Denai adalah menggunakan jaringan kerja yang luas. Strategi ini bertujuan untuk mendapatkan nasabah dalam jumlah yang banyak terutama nasabah yang potensial atau yang belum terjangkau oleh bank pesaing.

E. People (orang)

Dalam hal ini karyawan merupakan hal yang turut menentukan kegiatan operasinal PT. BPR Rangkiang Denai dalam penghimpunan dan penyaluran dana. Etika perorangan karyawan PT. BPR Rangkiang Denai harus patuh dan taat pada ketentuan perundang-undangan dan peraturan yang berlaku dan memberikan pelayanan yang memuaskan kepada nasabahnya. Karyawan pada PT.BPR Rangkiang Denai selalu senyum dan sabar dalam menghadapi nasabahnya, walaupun nasabah tersebut tidak sopan pada karyawan bank tersebut.

Dalam kegiatan untuk menjalin kedekatan seluruh karyawan dengan nasabahnya. PT. BPR Rangkiang Denai mengadakan senam bersama dengan nasabahnya setiap sekali dalam satu bulan, ini bertujuan untuk menjaga hubungan baik yang telah dijalin, sehingga nasabah merasa nyaman dan tidak berfikir untuk beralih ke bank lain.

F. Proses (proces)

Dalam hal ini PT. BPR Rangkiang Denai membuat prosedur dan mekanisme layanan secara sederhana dan tidak berbelit-belit sehingga nasabah tidak membutuhkan waktu yang panjang dalam melalui proses layanan tersebut. Contohnya pada proses penyetoran bank ini melakukan kerja lapangan, sehingga jika ada nasabah menabung, karyawan PT. BPR Rangkiang Denai siap untuk menjemput uang nasabahnya.

G. Pelayanan (customer service)

Dalam melayani nasabah hal-hal yang perlu diperhatikan adalah kepuasan nasabah terhadap pelayanan yang diberikan. Adapun pelayanan yang dilakukan PT. BPR Rangkiang Denai dalam memuaskan nasabah :

1. Menawarkan pelayanan jasa jemput bola, jadi setiap kali penyetoran ataupun penarikan tabungan ataupun deposito, nasabah tidak perlu repotrepot dan jauh-jauh datang ke kantor, cukup dengan telepon dan sms maka pegawai bank akan datang ke rumah nasabah.

2. Adanya kemudahan dalam transaksi pembukaan rekening Apabila transaksi pembukaan rekening tabungan dilakukan dengan mudah dan tidak mempersulit nasabah maka nasabah akan senang, nasabah mau melakukan transaksi lainnya dan tidak segan-segan memberitahu kepada orang lain tentang kemudahan bertransaksi di BPR Rangkiang Denai. Maka itu merupakan salah satu upaya yang dilakukan bank sekaligus mempromosikan bank atau produknya. 
3. Pelayanan yang memuaskan

Pelayanan yang memuaskan dari karyawan dan karyawati PT. BPR Rangkiang Denai kepada nasabah dengan melakukan transaksi offline, transaksi offline adalah transaksi secara langsung, dimana nasabah datang langsung pada bank tersebut. Ini juga menjadi salah satu strategi pemasaran produk yang efektif. Pelayanan ini dimulai dari kenyamanan parkir kendaraan nasabah yang aman dan luas, pelayanan dari security yang ada di depan pintu Akantor yang membukakan dan menutup pintu ketika nasabah datang.

Perkembangan Produk Tabungan Pada PT. BPR Rangkiang Denai Bulan Januari Mei 2015.

Pemasaran produk tabungan yang dilakukan oleh PT. BPR Rangkiang Denai berpengaruh pada perkembangan tabungan

Untuk mengetahui perkembangan jumlah nasabah tabungan pada PT. BPR Rangkiang Denai dari Bulan Januari 2015 - Mei 2015. Dapat dilihat pada tabel 1 di bawah ini adalah :

Tabel 1

Perkembangan Jumlah Nasabah dan Jumlah Nominal Dana Pada PT. BPR Rangkiang Denai Bulan Januari-Mei 2015

\begin{tabular}{|l|l|l|l|}
\hline No & Bulan & Jumlah Nasabah & Jumlah Nominal \\
\hline 1 & Januari & 89 & 215.355 .667 \\
\hline 2 & Februari & 87 & 143.102 .256 \\
\hline 3 & Maret & 87 & 140.394 .821 \\
\hline 4 & April & 20 & 136.281 .841 \\
\hline 5 & Mei & 19 & 92.638 .503 \\
\hline
\end{tabular}

Sumber : PT. BPR Rangkiang Denai Payakumbuh Barat

Dari tabel diatas BPR Rangkiang Denai dalam hal ini perkembangan jumlah nasabah tabungannya mengalami penurunan dari bulan ke bulan yang signifikan, ini terlihat dari bulan Januari 89 nasabah dengan nominal Rp. 215.355.667,--. Dan Mei 19 nasabah dengan nominal RP. 92.638.503,-. ini disebabkan oleh kegagalan BPR Rangkiang Denai dalam membaca kebutuhan konsumen, sehingga strategi pemasaran produk tabungan tidak berjalan sesuai harapan. Dan ini juga disebabkan oleh factor eksternal perusahaan diantaranya persaingan pangsa pasar, kemajuan teknologi dan kebutuhan nasabah yang semakin modern. Diera globalisasi nasabah cenderung lebih memilih bank yang memberikan jasa dalam lalu lintas pembayarannya, seperti jasa pngeriman uang, kliring, dan fasilitas seperti ATM untuk memudahkan transaksinya.

Seperti salah satu kebiasaan nasabah dalam berbelanja kebutuhan, nasabah sering bertransaksi dengan sistem online, dimana pembayaran melalui transfer lewat rekening atau lewat kliring. Jadi inilah sebab BPR tidak dilirik lagi oleh nasabah pada era globalisasi sekarang ini. 


\section{KESIMPULAN DAN SARAN \\ Kesimpulan}

Berdasarkan hasil pembahasan masalah yang diuraikan pada bab sebelumnya, maka penulis dapat mengambil kesimpulan sebagai berikut :

1. PT. BPR Rangkiang Denai menerapkan bauran pemasaran yaitu Produk, Harga, Tempat, Promosi, people, Proses dan pelayanan.

2. PT. BPR Rangkiang Denai memberikan bonus setiap bulan dan malakukan undian berupa satu unit sepeda motor kepada seluruh nasabah yang memiliki saldo tertinggi, sehingga nasabah selalu termotivasi untuk meningkatkan saldo tabungannnya.

3. Dalam menetapkan harganya PT. BPR Rangkiang Denai tidak mengenakan biaya administrasi kepada nasabah yang tergolong sebagai nasabah primer.

4. PT. BPR. Rangkiang Denai mengalami penurunan jumlah nasabah dari bulan januari-mei 2015. Penurunan tersebut di akibatkan karena pada zaman sekarang, BPR kurang diminati oleh masyarakat, karena di era globalisasi masyarakat lebih memilih bank yang memberikan jasa dalam lalu lintas pembayarannya, seperti pengiriman uang, dan fasilitas ATM untuk memudahkan transaksinya.

\section{Saran}

Berdasarkan kesimpulan di atas, maka penulis dapat memberikan saran sebagai berikut :

1. Meningkatkan strategi pemasaran produk-produk yang ditawarkan oleh PT. BPR Rangkiang Denai guna meningkatkan kepercayaan masyarakat kepada PT. BPR Rangkiang Denai khususnya dalam produk TAMADES (Tabungan Masyarakat Desa)

2. PT. BPR Rangkiang Denai harus lebih meningkatkan kualitas pelayanan terhadap nasabah dengan sistem kerja yang lebih baik, pola pikir, daya kreasi, saling koordinasi antara semua level.

3. PT. BPR Rangkiang Denai harus menciptakan promosi yang lebih gencar lagi untuk menarik calon nasabah seperti melakukan saluran promosi melalui komunikasi dari mulut ke mulut dan melakukan promosi melalui media televisi. 


\section{DAFTAR PUSTAKA}

Andika, A., \& Susanti, F. (2018). Pengaruh Marketing Mix Terhadap Keputusan Pembelian Parfum di Azzwars Parfum Lubeg Padang. https://doi.org/10.31227/osf.io/upgc3

Hidayati, R. R., \& Marlius, D. (2018). Aktivitas Promosi Dalam Meningkatkan Dana Pihak Ketiga Pada PT. Bank Perkreditan Rakyat (BPR) Batang Kapas Pesisir Selatan. https://doi.org/10.31227/osf.io/8dgqn

Kasmir, (2001), Bank dan Lembaga Keuangan Lainnya, Raja Grafindo Persada, Jakarta.

Kotler, Philip (2002), Manajemen Pemasaran II, PT. Prehalindo, Edisi Millenium. Jakarta.

Lupioyadi, Willem, (2001), Manajemen Pemasaran Jasa, Penerbit Salemba Empat, Jakarta.

Marlius, D. (2017). Keputusan Pembelian Berdasarkan Faktor Psikologis Dan Bauran Pemasaran Pada PT. Intercom Mobilindo Padang. Jurnal Pundi. Volume 1. No. 1. Hal. 57-66. https://doi.org/10.31575/jp.v1i1.9

Marlius, D. (2016). Pengaruh Bauran Pemasaran Jasa Terhadap Minat Nasabah Dalam Menabung Pada Bank Nagari Cabang Muaralabuh. https://doi.org/10.31227/osf.io/vdqgx

Sarwoto, Dasar - dasar Organisasi dan Manajemen. Penerbit Ghalia, Jakarta.

Sinungan, Murchdiansyah, (1993) Manajemen Dana Bank, Penerbit Bumi Aksara, Jakarta.

Staton, J William, (1986), Prinsip Pemasaran, Edisi Ke 7, Jilid 2, Penerbit Erlangga.

Sukanto R dan T. Hani Handoko, (1994) Teori dan Prilaku Organisasi Perusahaan. Penerbit BPFE, Yogyakarta.

Sumarni, Murni, (2000:162), Marketing Perbankan, Edisi 2, Penerbit Erlangga, Yogyakarta.

Susanti, F. (2015). Pengaruh Bauran Promosi Terhadap Keputusan Klien Dalam Memilih Radio Carano Sebagai Media Promosi Iklan. https://doi.org/10.31227/osf.io/b9ws7 
Susanti, F. (2014). Pengaruh Tarif Iklan Terhadap Pendapatan Pada PT. Radio Swara Carano Batirai Indah Batusangkar. https://doi.org/10.31227/osf.io/dy863

Susanti, F., \& Gunawan, A. C. (2019). Pengaruh Bauran Promosi Dan Harga Terhadap Keputusan Pembelian Produk Kosmetik Maybelline Di Kota Padang. https://doi.org/10.31227/osf.io/npjqh

Undang - Undang RI No. 10 Tahun 1998, (1999), Tentang Perbankan. Penerbit Sinar Grafika. Cetakan Kedua. 